\title{
Pesticide Residues in Conventionally and Organically Managed Apiaries in South and North Florida
}

\author{
Lambert HB Kanga $^{1 *}$, Shalom C Siebert ${ }^{1}$, Mehboob Sheikh ${ }^{1}$ and Jesusa Crisostomo Legaspi ${ }^{2}$ \\ ${ }^{1}$ Center for Biological Control, Florida A\&M University, College of Agriculture and Food Sciences, USA \\ ${ }^{2}$ United States Department of Agriculture - Agricultural Research Service - Center for Medical, Agricultural and Veterinary Entomology, \\ USA
}

*Corresponding author: Lambert HB Kanga, Center for Biological Control, Florida A\&M University, College of Agriculture and Food Sciences, 310 Perry Paige Building South, Tallahassee, FL 32307, USA

\begin{abstract}
Background: Honeybees are of economic importance not only for honey production but also for crop pollination. Nationwide, the value of the increased crop yield and quality achieved by honeybees is estimated at $\$ 14.6$ billion. Thus, bee health is critical for the success of pollination-based agriculture, which produces about a third of our diet in the United States (US). Unfortunately, the number of honeybee colonies in the US has declined by more than $40 \%$ in the last few years. A combination of causal factors, including exposure to pesticides, parasites, and beekeeping practices are believed to be the culprit for the increased colony mortality. In this study, we compared pesticide residues under two different beekeeping management practices (conventionally and organically-managed apiaries).

Results: We found no pesticide residues in adult bee samples collected from organically managed hives; whereas, trace amounts of the fungicide chlorothalonil and the pyrethroid insecticide fluvalinate were found in adult bees collected from conventionally managed hives. Unlike honey harvested from organically managed hives, a concentration of $12.45 \mathrm{ppb}$ of the formamidine amitraz was found in honey harvested from conventionally managed hives. Residues of several pesticides were found in wax from both conventionally and organically managed apiaries; except for coumaphos at $225.3 \mathrm{ppb}$, levels were generally lower in organically managed hives and the highest concentration of insecticide detected in wax from conventionally managed hives was fluvalinate at $251.5 \mathrm{ppb}$. Two pyrethroid insecticides (fluvalinate and bifenthrin) were found in pollen samples collected from organically managed hives; in contrast, several classes of pesticides were detected in pollen samples from conventionally managed hives where the highest residue level was that of the fungicide pyraclostrobin at $100 \mathrm{ppb}$.
\end{abstract}

Conclusion: In general, pesticide residues were higher in conventionally managed apiaries than in organically managed ones. There were more chemical residues in the pollen samples from conventionally managed apiaries than organically managed ones. Farmers and beekeepers should work together to promote honeybee health.

Keywords: Honeybees; Conventionally managed hives; Pesticide residues

\section{Introduction}

Agricultural intensification has caused an increase in the use of pesticides in cropping systems[1]. Unfortunately, the dependence upon pesticides in agricultural systems can have an unfavorable effect on pollinator populations, specifically the surrounding managed and native bee populations [2]. In the United States, honeybees (Apis mellifera L., Hymenoptera: Apidae) are regularly exposed to pesticides, most of which are either moderately or highly toxic [3]. Beekeepers follow the bloom periods of agricultural crops and transport their bees to various locations for pollination services, creating an environment that promotes pesticide exposure for honeybees. Although organically managed bees are on land that uses no pesticides, the beekeeper cannot control where the bees forage [4]. With the introduction of the honeybee pests Varroa destructor Anderson \& Trueman (Parasitoformes: Varroidae) and Aethina tumida Murray (Coleoptera: Nitidulidae), beekeepers frequently treat their hives with chemicals [5]. Consequently, honeybee populations are directly exposed to these chemicals. 
Frazier et al. [6] raised concerns on the use of the pyrethroid fluvalinate in hives for the control of Varroa mites as this chemical is toxic to honeybees. Pyrethroids can decrease the number of honeybee colonies and their effectiveness as pollinators [7]. Another pyrethroid (deltamethrin) disrupts the homing flight of honeybees [8], and the proboscis extension response was negatively affected by sublethal doses of several synthetic pyrethroids [9].

Sublethal effects due to the presence of the organophosphate coumaphos can have a detrimental effect on honeybees even when applications are made according to the label and best management practices are used $[6,10,11]$. Smodiš Škerl et al. [10] reported that coumaphos treatments induced reduction in the size of hypopharyngeal gland acini and heat shock protein localization in cell nuclei and cytoplasm. Coumaphos has also been reported to trigger an increased level of programmed cell death in honeybees [12]. Honeybee foragers collect pollen and nectar from flowers to sustain the colony; however, residues that are found in plants can be transferred to brood through pollen, wax, or brood food contamination [13]. Pollen is the main protein source of brood and is necessary for the growth and development of individual honeybee and consequently for colony growth [3]. Pesticide residues found in pollen loads and bee bread that are fed to brood and adult bees can have an adverse impact on development and longevity [10]. Pesticides also have the potential to affect bees by impairing learning abilities and suppressing immune systems [6]. Because the implications of pesticides to honeybee health are significant [13], it is important to evaluate the prevalence of pesticide residues in adult bees and their products when analyzing honeybee health. In this study, we compared the prevalence of chemical residues in conventionally-managed and organically-managed hives in north and south Florida to determine whether beekeeping practices affected levels of pesticide residues in honeybee colonies.

\section{Materials and Methods}

\section{Sampling of hive products and pesticide residue analysis}

Honey, pollen, wax and adult bees were sampled from honeybee colonies maintained in conventionally and organically managed apiaries in north and south Florida. In north Florida, 10 organically managed hives and 10 conventionally managed hives were sampled in Monticello. In south Florida, 15 organically managed hives and 8 conventionally managed hives were sampled in Loxahatchee. We used the sampling methods described by Frazier et al. [6]. Briefly, two-ounce samples (about $56.5 \mathrm{~g}$ ) of honey, wax, pollen, and adult bees were taken directly from each hive and placed into clean, crush-proof, leak-proof, plastic containers (Rubbermaid $®$ ). Plastic containers were labeled according to hive number and type of sample and immediately placed on ice until transfer to an $-80^{\circ} \mathrm{C}$ freezer [3]. The samples of pollen, wax, honey, and adult bees that were collected from apiaries in north and south Florida were held in $-80^{\circ} \mathrm{C}$ freezer until shipment. All samples were shipped to Maryann Frazier (Pennsylvania State University) and they were subjected to a broad-spectrum pesticide analysis for 200 chemicals using liquid chromatography mass spectrometry and gas chromatography mass spectrometry with a modified QuEChERS method using the procedure as described from Mullin et al. [3]. Samples (honey, pollen, wax and adult bee matrices) of $3 \mathrm{~g}$ were weighed into a 50 $\mathrm{ml}$ plastic centrifuge tube and fortified with $100 \mu \mathrm{l}$ of the process control spiking (PCS) solution. A $27 \mathrm{ml}$ of extraction solution (44\% deionized water, $55 \%$ acetonitrile, and $1 \%$ glacial acetic acid), was added to each sample with $100 \mu \mathrm{l}$ of the internal standard (ISTD) spiking solution. Six g of anhydrous magnesium sulfate $\left(\mathrm{MgSO}_{4}\right)$ and $1.5 \mathrm{~g}$ anhydrous sodium acetate were added to each sample.

The tubes were sealed and shaken vigorously for 1 minute, centrifuged, and $1 \mathrm{ml}$ of supernatant or its concentrate transferred to a $2 \mathrm{ml}$ mini-centrifuge tube that contains $0.05 \mathrm{~g}$ primary secondary amine, $0.05 \mathrm{~g} \mathrm{C} 18$, and $0.15 \mathrm{~g} \mathrm{MgSO}_{4}$. The tubes were vortexed for 1 minute and centrifuged; the resulting supernatant was transferred to an auto-sampler vial for analysis by LC/MS-MS using a $3.5 \mu \mathrm{m}, 2.1 \times 150 \mathrm{~mm}$ Agilent Zorbax SB-C18 column and an Agilent 1100 LC with a binary pump interfaced to a ThermoFisher TSQ Quantum Discovery triple quadrupole MS. To conduct the Gas chromatography (GC) analyses, a dual layer solid-phase extraction (SPE) cartridge containing $250 \mathrm{mg}$ of graphitized carbon black (GCB) and $500 \mathrm{mg}$ of PSA was prepared with approximately $0.80 \mathrm{~g}$ of anhydrous $\mathrm{MgSO}_{4}$ added to the top of the cartridge. After conditioning the SPE cartridge by adding one cartridge volume $(4.0 \mathrm{ml})$ of acetone/toluene $(7: 3 ; \mathrm{v} / \mathrm{v})$ using a positive pressure SPE manifold and eluting to waste, $2 \mathrm{ml}$ of supernatant obtained previously was applied to the cartridge. The components of the pesticides were eluted with 3 by $4 \mathrm{ml}$ of acetone/toluene (7:3; $\mathrm{v} / \mathrm{v}$ ) into a $15 \mathrm{ml}$ graduated glass centrifuge tube. Using an N-Evap at $50{ }^{\circ} \mathrm{C}$, eluates were dried using toluene and concentrated to a final volume of $0.4 \mathrm{ml}$ for analysis using GC/MS in the electron impact and negative chemical ionization modes. An Agilent 6890 GC equipped with a $0.25 \mathrm{~mm}$ id×30 m J\&W DB-5MS ( $2 \mu \mathrm{m}$ film) capillary column interfaced to an Agilent 5975 triple quadrupole MS was used [3].

\section{Statistical Analysis}

A chi-square test of association was used to assess the prevalence of pesticide residues in honey, wax, and pollen between the two groups (conventionally and organically managed apiaries). Statistical analysis was carried out using SAS model (PROC FREQ) [14]. Significant differences between compounds were determined at the $\mathrm{P}<0.05$ level.

\section{Results and Discussion}

\section{Pesticide residues in adult honeybees and honey samples}

No pesticide residues were detected in adult bee samples collected from organically managed hives. However, trace amounts of the fungicide chlorothalonil and the pyrethroid fluvalinate were detected in the samples from conventionally managed hives. The samples of honey collected from organically managed hives had no pesticides; in contrast, a concentration of $12.45 \mathrm{ppb}$ of the formamidine amitraz was detected in honey collected from conventionally managed hives. Our data provided useful insights for the development of best beekeeping practices and implications on regulatory policies related to pollinator safety and environmental and public safety concerns. 


\section{Pesticide residues in wax samples}

Pesticide residues were found in wax samples from organically managed hives; these included the pyrethroid fluvalinate at 54.85 $\mathrm{ppb}$, the organophosphate coumaphos at $225.30 \mathrm{ppb}$, and the systemic fungicide carbendazim at $12.30 \mathrm{ppb}$. Trace amounts of the fungicide chlorothalonil and the pyrethroid cylohalthrin were also detected in wax samples from organically managed hives. In contrast, the levels of residues in conventionally managed hives were 4.6-fold higher for the pyrethroid fluvalinate and 4.1-fold lower for the organophosphate coumaphos (Figure 1). Residues of the formamidine amitraz (17.6 ppb) and the pyrethroid cypermethrin (6.55 ppb) were present in wax samples from conventionally managed hives, as were trace amounts of the herbicide trifluralin (Figure1). The levels of pesticide residues were significantly different between conventionally managed hives and organically managed hives $(\chi 2=264.47 ; \mathrm{df}=4 ; \mathrm{p}<0.0001)$. Although higher residue levels were generally found in conventionally managed hives, the binary combination of fluvalinate and coumaphos was found in wax samples from both conventionally and organically managed hives (Figure 1). Wax foundations are sheets of pressed wax that beekeepers use as templates for comb construction [15]. The chemicals fluvalinate and coumaphos are frequently used by conventional beekeepers for in-hive treatments to control the Varroa mite and the small hive beetle $[16,6]$. Organic beekeepers do not use chemical treatments; thus, the high levels of coumaphos found in wax samples from organically managed hives were due to previous contaminations of the wax foundation at the time of purchase by the beekeeper (personal communication from organic beekeepers). The contamination of wax is a problem recognized in previous studies $[3,16]$, and more recent research attempted to standardize the source of wax [17]. High levels of insecticide residues in wax are issues of concern as persistent chemicals can provide a toxic environment in the bee colonies and negatively affect honeybee health. The number of honeybee colonies in the U.S. has continued to decline in the last decades [18]. Colony losses have occurred concurrent with an increasing demand for the pollination of fiber, fruit, vegetable and nut crops especially almonds [19]. Because of deleterious impact of pesticides on honeybees, more emphasis should be towards chemical-free beekeeping practices using biological control and genetic control for honey bee pests $[16,20]$.

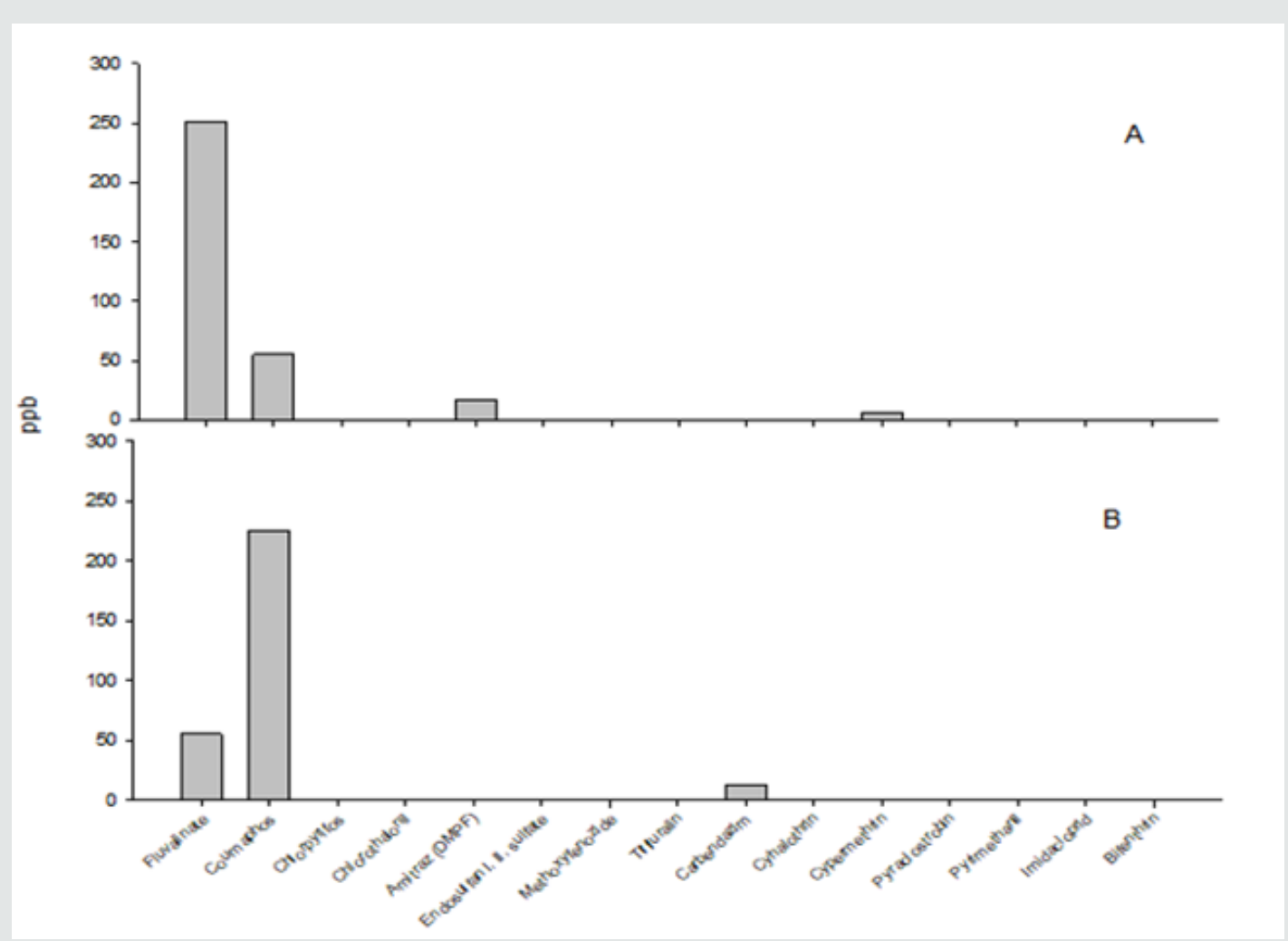

Figure 1: Pesticide residues in wax samples from conventionally (A) and organically-managed (B) hives. Concentrations of chemical residues are expressed in part per billion $(\mathrm{ppb})$.

\section{Pesticide residues in pollen samples}

The pyrethroid fluvalinate was detected at a concentration of $4.6 \mathrm{ppb}$ and bifenthrin at $18.3 \mathrm{ppb}$ in samples of pollen collected from organically managed hives (Figure 2). The levels of residues in conventionally managed apiaries varied between pesticide classes with the highest level being that of the fungicide pyraclostrobin (100 ppb). The pyrethroid insecticides detected in pollen included fluvalinate at $4.6 \mathrm{ppb}$, cyhalothrin at $8.05 \mathrm{ppb}$, bifenthrin at 9.15 $\mathrm{ppb}$, and trace amounts of cypermethrin. There were also residues of the organophosphate chlorpyrifos at $2.85 \mathrm{ppb}$, the cyclodiene endosulfan (I, II isomers and sulfate) at $19.5 \mathrm{ppb}$, the neonicotinoid imidacloprid at $5.6 \mathrm{ppb}$, and the fungicides carbendazim at 10.7 ppb and pyrimethanil at $8.7 \mathrm{ppb}$ (Fig. 2). The loads of residues of pesticides detected in pollen were significantly higher in 
conventionally managed apiaries $(\chi 2=133.14 ; \mathrm{df}=9$; $\mathrm{p}<0.0001)$. More chemical residues were found in the pollen samples from conventionally managed hives $(89.82 \%)$ than organically managed ones $(10.18 \%)$. This suggests a wide range of plant hosts from which pollen is collected by honeybees. Pollen is the main source of protein, vitamins, lipids, and amino acids that contribute to honeybee development and survival [21]. Therefore, the exposure to pesticide residues in the pollen samples from conventionally managed hives, could adversely impede honeybee health [3]. Despite the organic beekeepers attempt to control the honeybee's exposure to pesticides, the beekeeper cannot control the foraging activities of the honeybees. Thus, it is difficult to lessen the amount of contacts that honeybees have with chemically contaminated pollens. This is evident in the amount of different pesticide residues found in the pollen from conventionally managed and organically managed hives. Because bee health is critical for the success of pollination-based agriculture, which produces about one-third of the diet in the United States; farmers and beekeepers should work together to create an environment that promotes less contamination for honey bee foragers and provides a suitable habitat for bee growth and development [22].

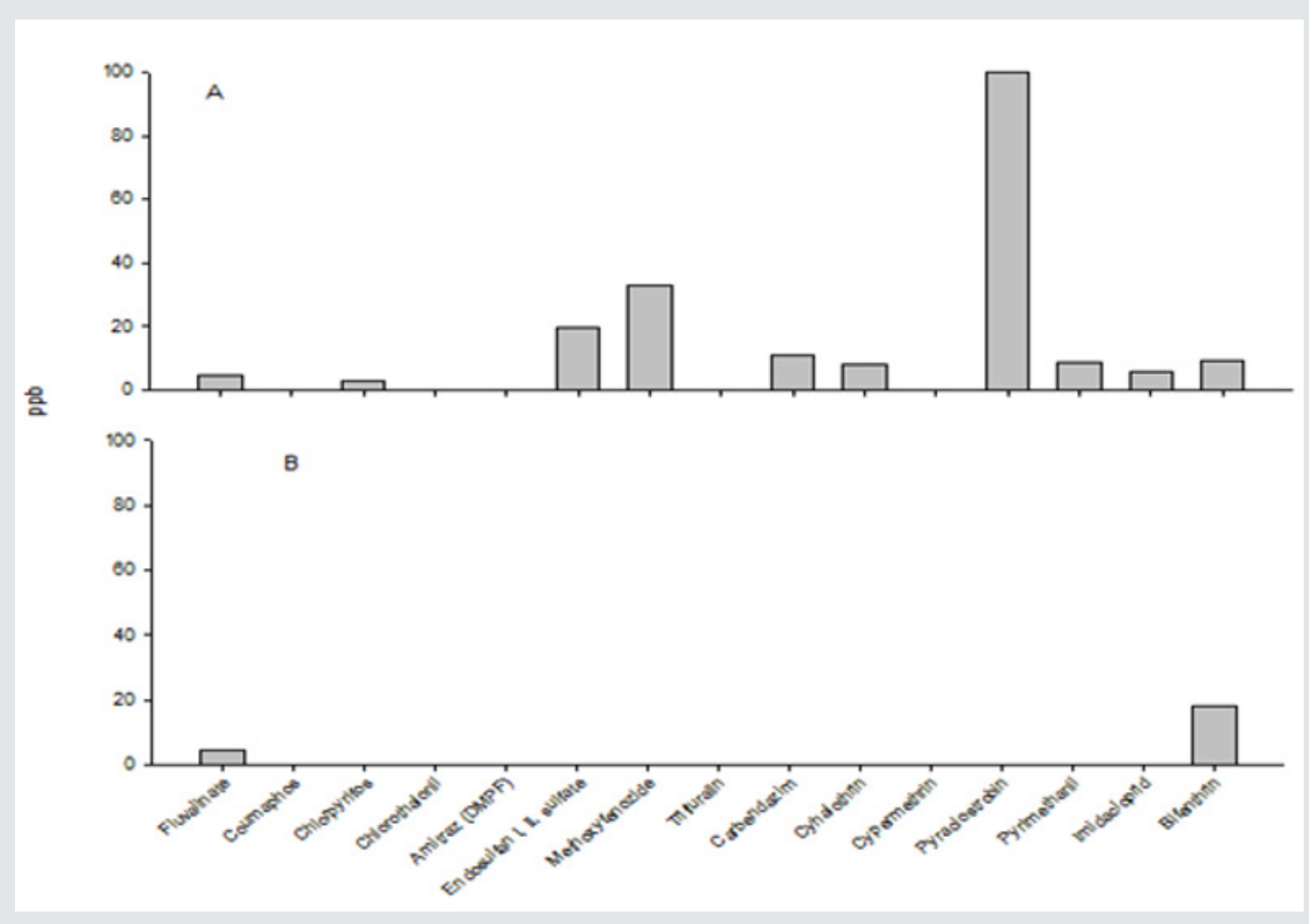

Figure 2: Pesticide residues in pollen samples from conventionally (A) and organically-managed (B) hives. Concentrations of chemical residues are expressed in part per billion (ppb).

\section{Acknowledgment}

We are grateful to Ms. Janice Peters, Dr. Benjamin Hottel (Florida A\&M University) and Dr. Benjamin Legaspi, Jr. for providing useful discussions and reviews of the manuscript. We also thank Dr. Maryann Frazier (Pennsylvania State University) for the residue analysis and Mr. Julius Eason (Florida A\&M University) for his technical assistance with this study. This study was supported by the Grant \# 2014-38821-22401from the USDA-NIFA Capacity Building Program.

\section{References}

1. Hein L (2009) The economic value of the pollination service, a review across scales. The Open Ecology Journal 2: 74-82.

2. Morandin LA, Winston ML (2005) Wild bee abundance and seed production in conventional, organic, and genetically modified canola. Ecological Applications 15(3): 871-881.
3. Mullin CA, Frazier M, Frazier JL, Ashcraft S, Simonds R, et al. (2010) High levels of miticides and agrochemicals in North American apiaries: implications for honeybee health. PLoS ONE 5(3): e9754.

4. Collison C (2018) A closer look - foraging behavior. Bee Culture.

5. Nanetti A, Rovida A, Piazza P, Martini A, Besana AM, et al. (2006) Treatments of honey bee colonies affected by Varroa destructor in organic apiculture. Paper at: Joint Organic Congress, Odense, Denmark, 30-31.

6. Frazier MT, Mullin C, Frazier J, Ashcroft S (2008) What have pesticides got to do with it? American Bee Journal 148: 521-523.

7. Maini S, Medrzycki P, Porrini C (2010) The puzzle of honeybee losses: a brief review. Bulletin of Insectology 63(1): 153-160.

8. Vandame R, Meled M, Colin M, Belzunces LP (1995) Alteration of the homing-flight in the honey bee Apis mellifera $L$. exposed to sublethal doses of deltamethrin. Environmental Toxicology and Chemistry 14(5): 855-860. 
9. Taylor KS, Waller GD, Crowder LA (1987) Impairment of a classical conditioning response of the honeybee (Apis mellifera $L$ ) by sublethal doses of synthetic pyrethroid insecticides. Apidologie 18(3): 243-252.

10. Smodiš Škerl MI, Bolta SV, Cesnik HB, Gregorc A (2009) Residues of pesticides in honeybee (Apis mellifera carnica) bee bread and in pollen loads from treated apple orchards. Bulletin of Environmental Contamination and Toxicology 83(3): 374-377.

11. Ellis J (2007) Colony collapse disorder (CCD) in honey bees. UF IFAS Extension, University of Florida ENY-150.

12. Smodiš Škerl MI, Kmecl V, Gregorc A (2010) Exposure to pesticides at sublethal level and their distribution within a honey bee (Apis mellifera) colony. Bulletin of Environmental Contamination and Toxicology 85(2): 125-128.

13. Gregorc A, Evans J, Scharf M, Ellis J (2012) Gene expression in honeybee (Apis mellifera) larvae exposed to pesticides and Varroa mites (Varroa destructor). Journal of Insect Physiology 58(8): 1042-1049.

14. SAS Institute. 2006. The SAS system for Windows. Cary, NC: SAS Institute Inc.

15. Johnson RM, Ellis MD, Mullin CA, Frazier M (2010) Pesticides and honeybee toxicity-USA. Apidologie 41(3): 312-331.
16. Kanga LHB, Jones WA, James RR (2003) Field trials using the fungal pathogen, Metarhizium anisopliae (Deuteromycetes: Hyphomycetes) to control the ectoparasitic mite, Varroa destructor (Acari: Varroidae) in honey bee, Apis mellifera (Hymenoptera). Biological and Microbial Control 96(4): 1091-1099.

17. Ostiguy N, Drummond FA, Aronstein K, Eitzer B, Ellis JD, et al. (2019) Honey bee exposure to pesticides: a four-year nationwide study. Insects 10(1): 13.

18. NASS (2008) National Agricultural Statistics Service Honey.

19. VanEngelsdorp D, Meixner MD (2010) A historical review of managed honey bee populations in Europe and the United States and the factors that may affect them. Journal of Invertebrate Pathology 103: s80-s95

20. Rinderer TE, Kuznetsov VN, Danka RG, Delatte GT (1997) An importation of potentially Varroa-resistant honey bees from far-eastern Russia. American Bee Journal 137: 787-789.

21. Brodschneider R, Crailsheim K (2010) Nutrition and health in honey bees. Apidologie 41: 278-294.

22. Naug D (2009) Nutritional stress due to habitat loss may explain recent honeybee colony collapses. Biological Conservation 142: 2369-2372.

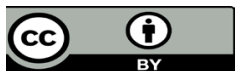

This work is licensed under Creative Commons Attribution 4.0 License

To Submit Your Article Click Here: Submit Article

DOI: $10.32474 /$ CIACR.2019.07.000262

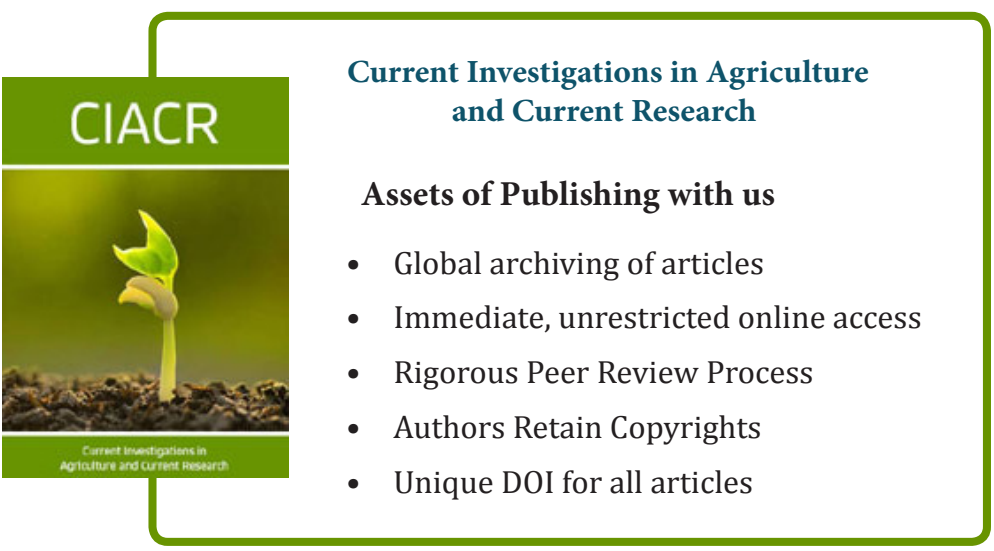

